\title{
Prevalence of Mixed Infections among Females with Vaginitis in a Tertiary Care Center
}

\author{
Dr. K. Gayathri M. D., DVL ${ }^{1}$, Dr. S. Kalaivani M. D., D. ${ }^{2}$ \\ ${ }^{1}$ Assistant Professor of STD, Institute of Venereology, Madras Medical College, Chennai -600003, Tamil Nadu, India \\ ${ }^{2}$ Director \& Professor of STD, Institute of Venereology, Madras Medical College, Chennai -600003, Tamil Nadu, India
}

\begin{abstract}
Introduction: Vaginal discharge is a common problem among women and is associated with significant morbidity. Mixed infections are one among the causes of vaginal discharge. Aim: To study the prevalence of mixed infections in patients with vaginitis in a tertiary care center. Materials and Methods: A Retrospective observational study was conducted in a tertiary care center from Jan 2014- Dec 2015. Total of 7378 females of all age groups who were willing for examination were included in the study. Results: Among the total 7378 females, 1499 (20.3\%) females were detected to have vaginitis. Most common infection noted was BV (47\%) followed by VVC (38\%). Prevalence of mixed infection was $7 \% .76 \%$ were in the age group of $20-49$ yrs. $94 \%$ were married. $14 \%$ were RVD positive. $37 \%$ were asymptomatic. Conclusion: Women with asymptomatic infections are at high risk of having undetected complications and may be a hidden reservoir.
\end{abstract}

Keywords: Bacterial Vaginosis (BV), Trichomoniasis(TV),Vulvovaginal Candidiasis (VVC), Retroviral Disease (Rvd), Mixed Infections

\section{Introduction}

Vaginal discharge is a common problem among women and is associated with significant morbidity. Early diagnosis and appropriate treatment is essential. Mixed infections are found to be one among the causes of vaginal discharge.

\section{Aim and Objective}

To study the prevalence of mixed infections in patients diagnosed with vaginitis in a tertiary care center

\section{Materials and Methods}

A Retrospective observational study was conducted in a tertiary care center over a period of two years from Jan 2014- Dec 2015. Newly registered female clinic attendees of all age groups were studied. Total of 7378 females who were willing for examination were included. Pregnant and menstruating women were not included.
General examination, Genital examination \& Per speculum examination was done. Specimen was collected for saline wet mount preparation, $10 \% \mathrm{KOH}$ preparation, gram stain and culture for candida, Trichomonas vaginalis, \& gonococci. Serology for HIV, VDRL was done.

Bacterial vaginosis was diagnosed by modified Amsel's criteria $(>20 \%$ clue cells $)$.Vaginal candidiasis was diagnosed by $10 \% \mathrm{KOH}$ wet mount and gram staining showing budding spores and pseudohyphae. Trichomoniasis was diagnosed by presence of motile flagellated protozoa.

\section{Results}

Among the study population of 7378 females, 1499(20.3\%) females were detected to have vaginitis. Most commonly affected age group was 20-39 years. (Table:1)

Table 1: Age Distribution

\begin{tabular}{|c|c|c|c|c|c|c|c|}
\hline Age & Total & $\begin{array}{c}\text { TV+ } \\
\text { candida }\end{array}$ & $\begin{array}{c}\text { B V+ } \\
\text { candida }\end{array}$ & $\begin{array}{c}\text { B V+ } \\
\text { TV }\end{array}$ & BV & TV & Candida \\
\hline$<20$ yrs & 770 & 1 & 4 & 0 & 64 & 12 & 50 \\
\hline $20-29$ yrs & 1329 & 5 & 12 & 6 & 245 & 42 & 150 \\
\hline $30-39$ yrs & 1952 & 7 & 26 & 11 & 218 & 35 & 160 \\
\hline $40-49$ yrs & 1997 & 3 & 22 & 8 & 105 & 19 & 100 \\
\hline$>50 y r s$ & 1330 & 3 & 0 & 0 & 80 & 10 & 103 \\
\hline TOTAL & 7378 & 19 & 63 & 25 & 712 & 118 & 563 \\
\hline
\end{tabular}

Distribution of Retroviral disease among the mixed infection was $\mathrm{BV}+\mathrm{VVC}-12, \mathrm{BV}+\mathrm{TV}-10$, TV $+\mathrm{VVC}-8.93 \%$ were married among the study population.

Among the 1499 patients, Bacterial vaginosis was 712 (47\%), followed by Vulvovaginal Candidiasis 563(38\%) and Trichomoniasis $118(8 \%)$.

\section{Mixed infection constituted 106 (7\%).}

Percentage of distribution of mixed infection is shown in (Fig. No.1) 


\section{International Journal of Science and Research (IJSR) \\ ISSN (Online): 2319-7064}

Index Copernicus Value (2015): 78.96 | Impact Factor (2015): 6.391

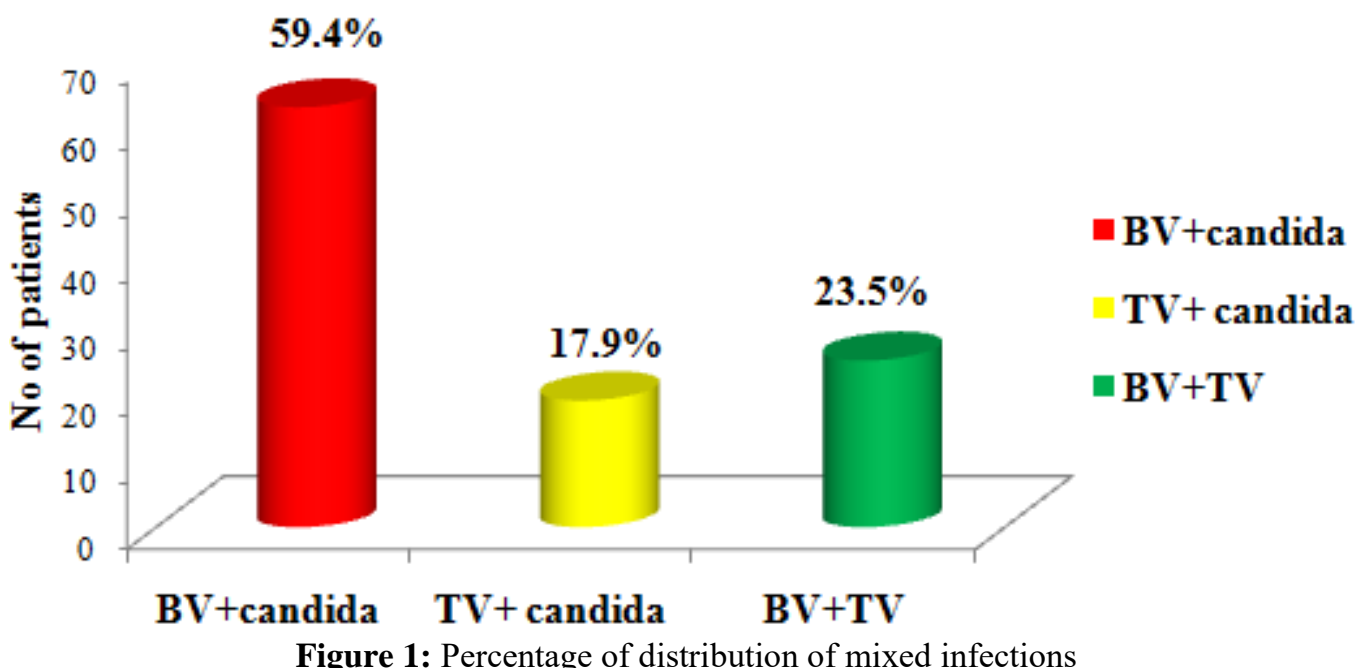

$37 \%$ of Females with mixed infection were Asymptomatic (Fig No.2)

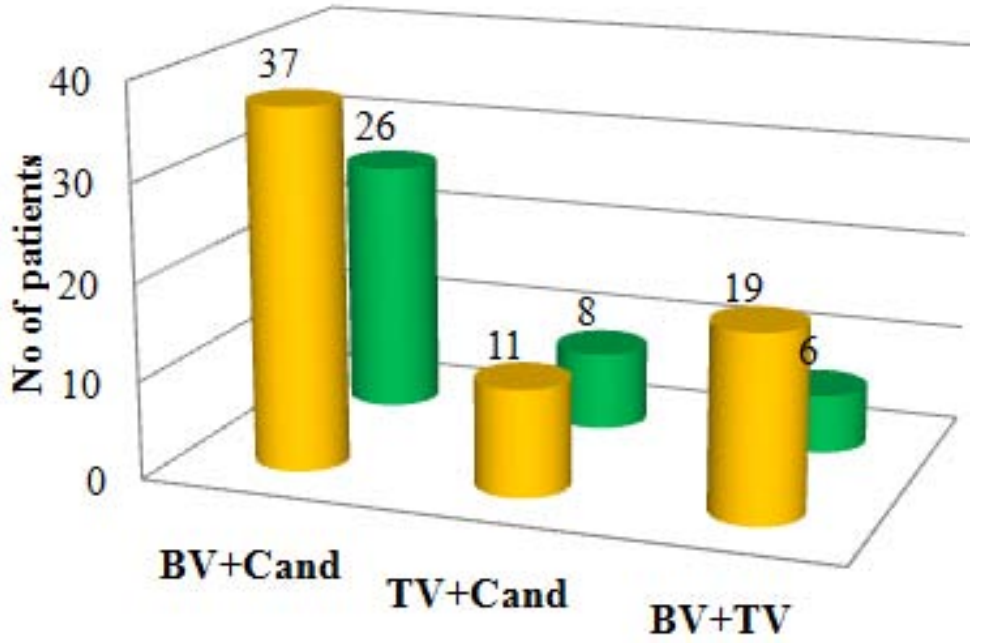

\begin{tabular}{|l|c|c|c|}
\cline { 2 - 4 } \multicolumn{1}{c|}{} & BV+Cand & TV+Cand & BV+TV \\
\hline Symptomatic & 37 & 11 & 19 \\
\hline Asymptomatic & 26 & 8 & 6 \\
\hline
\end{tabular}

Figure 2

\section{Discussion}

\section{Bacterial Vaginosis}

Bacterial vaginosis is a polymicrobial syndrome characterized by disturbance in the vaginal ecosystem where normal lactobacilli is replaced with overgrowth of anaerobic and facultative vaginal commensal organisms.

The most common infection noted was BV (47\%) followed by VVC (38\%) which was similar to the study done by Puri (1) et al on the various cause of vaginal discharge among females in sexually active group where BV was $(45 \%)$ and VVC (31\%).

Prevalence of bacterial vaginosis in the present study was $10.7 \%$.

Prevalence is less compared to study done by Anuradha et $\mathrm{al}^{(2)}$ in which prevalence was $17.3 \%$.

\section{Trichomoniasis}

Trichomoniasis is the most common curable sexually transmitted disease affecting sexually active group. It is associated with complications such as infertility, increased risk of acquiring HIV and other STD. Prevalence of Trichomoniasis in this study was $1.8 \%$ which is comparable with prevalence of $1.8 \%$ in study by Anuradha et al and $1.18 \%$ in $\mathrm{Rao}^{(3)}$ study. Prevalence of Trichomoniasis in HIV reactive group was $32 / 208(15 \%)$ which is similar (15\%) to study done by Hutton Rose et al ${ }^{(4)}$.

\section{Vulvovaginal Candidiasis}

Vulvovaginal candidiasis is common condition affecting $75 \%$ of reproductive adult women atleast once in their lifetime. It is seen in high percentage among pregnant, immuno suppressed and women on oral contraceptive pill. Prevalence of VVC in this study was $7.7 \%$ which almost coincides with VVC prevalence $(7.5 \%)$ in a study by Pawanarkar and Chopra ${ }^{(5)}$ who studied lower tract infection among infertile women. 


\section{International Journal of Science and Research (IJSR) \\ ISSN (Online): 2319-7064}

Index Copernicus Value (2015): 78.96 | Impact Factor (2015): 6.391

Mixed infections have significant clinical and therapeutic implications. Prevalence of mixed infection in this study was $7 \%$ which is higher than study by Sivaranjini ${ }^{(6)}$ et al $(5.5 \%)$ on spectrum of vaginal discharge in a tertiary center.

Prevalence of BV with candidiasis was $4.2 \%$ comparable with Rivers ${ }^{(7)}$ study with prevalence of $4.4 \%$ (prevalence of bacterial vaginosis and candida mixed infection in a STD clinic).

Prevalence of Trichomoniasis with Bacterial vaginosis was $1.6 \%$.

Prevalence of Trichomoniasis with Candidiasis was 1.2\%.

\section{Conclusion}

Women with asymptomatic infections are at high risk of having undetected complications and may be a hidden reservoir. All reproductive aged females should be routinely screened for reproductive tract infections which would help in right diagnosis and timely management. Emphasis should be given to reproductive health care and point of care screening which could dramatically improve the health of females and reduce the risk of acquisition of HIV and other STD related gynecological complications such as infertility, pelvic inflammatory disease, adverse pregnancy outcomes.

\section{References}

[1] Incidence of various causes of vaginal discharge among sexually active females in age group 20-40 years. Puri KJ, Madan A, Bajaj Year : 2003 | Volume : 69 | Issue : 2 | Page : 122-125

[2] Clinicoetiological Characterization of Infectious Vaginitis amongst Women of Reproductive Age Group from Navi Mumbai, Anuradha Narayankhedkar, ${ }^{1}$ Anahita Hodiwala, ${ }^{2}$ and Arati Mane ${ }^{3}$ IndiaJ Sex Transm Dis. 2015; 2015: 817092. doi: $10.1155 / 2015 / 817092$.

[3] Diagnosis of bacterial vaginosis in a rural setup: Comparison of clinical algorithm, smear scoring and culture by semiquantitative technique Year: 2004 | Volume : 22 | Issue : 1 | Page : 47-50. PS Rao, S Devi, A Shriyan, M Rajaram, K Jagdishchandra

[4] The prevalence of other sexually transmitted infections in confirmed HIV cases at a referral clinic in Jamaica. 2008 Sep;128(5):242-7. Hutton-Rose $\mathrm{N}^{1}$, Blythe C, Ogbonna C, McGrowder D.

[5] Prevalence of lower reproductive tract infection in infertile women. Health Popul Perspec Pawanarkar J, Chopra K. t Issues 2004;27:75.

[6] Spectrum of vaginal discharge in a tertiary care setting $R$ Sivaranjini, TJ Jaisankar Year 2013 vol3 issue2 page135139

[7] Prevalence of bacterial vaginosis and vulvovaginal candidiasis mixed infection in a southeastern american STD clinic. 2011 Jul;38(7):67doi: 10.1097/OLQ.0b013e31820fc3b8. Rivers $\mathrm{CA}^{1}$, Adaramola OO, Schwebke JR. 